\title{
An Investigation of Meteorological Drought Studies on a Global Scale Using a Bibliometric Analysis
}

\author{
Mustafa Utku Yilmaz ${ }^{*(1)}$, Hülya Yilmaz ${ }^{2}$ \\ 1* Department of Civil Engineering, Kirklareli University, 39100 Kirklareli, TURKEY \\ ${ }^{2}$ Quality Coordination Office, Kirklareli University, 39100, Kirklareli, TURKEY
}

\begin{abstract}
Cite this paper as:
Yilmaz, M. U. and Yilmaz, H. (2022). An Investigation of Meteorological Drought Studies on a Global Scale Using a Bibliometric Analysis. Journal of Innovative Science and Engineering. 6(1):76-93

*Corresponding author: Mustafa Utku E-mail:utkuyilmaz@klu.edu.tr
\end{abstract}

Received Date:09/09/2021

Accepted Date:02/12/2021

(C) Copyright 2022 by

Bursa Technical University. Available online at http://jise.btu.edu.tr/

\section{(c) (i) (8)}

The works published in Journal of Innovative Science and Engineering (JISE) are licensed under a Creative Commons Attribution-NonCommercial 4.0 International License.

\section{Abstract}

In this study, meteorological drought-related studies (drought analysis, drought monitoring, and drought prediction) published between 1980 and 2021, which are based on the Scopus database, were comprehensively investigated using bibliometric analysis. 1346 publications were assessed according to several indicators including publication types, year of publication, countries, journals, authors, keywords, the title of publication, and the number of citations. The results of the analysis were visualized with the VOSviewer software. The results indicated that the number of publications increased gradually from 2013 to 2018 , followed by a sharp increase from 2019 to 2020 . This shows that the importance of studies in the field of meteorological drought on a global scale has increased considerably in recent years. However, about $77 \%$ of the authors published only one publication in the investigated period. Results of Lotka's law, Price's law, and Pareto's law revealed that there were very few highly productive authors. China and the United States were the first two countries among 117 countries in terms of the number of publications they produce. Turkey was the ninth country in the ranking of the countries with the highest number of publications with 46 . The journal that published the most publications in this field is the Journal of Hydrology with 53 publications. The most-cited journal was Water Resources Management with 1710 citations. The increase in the number of publications after 2019 was also reflected in the number of citations. About $60 \%$ of the total number of citations in the investigated period were in the last 3 years. This shows that many researchers have recently drawn their attention to this field recently. This also indicates that studies on meteorological drought will increasingly continue. These findings will serve as an instructive guide for researchers in this field.

Keywords: Bibliometric analysis, drought, meteorological drought, scopus, VOSviewer. 


\section{Introduction}

Drought is a long-term, recurrent, and severe natural event that affects large areas and causes serious damage to human life and economic losses. Generally, it is defined as an absence of sufficient precipitation over long periods [1]. It can occur at any time and in any region. It develops slowly, but it is not easy to determine the beginning and the end correctly. Therefore, it has a different characteristic from other natural disasters. Drought is among the global risks that threaten the future of humanity. Towards the end of the 21 st century, drought trends are expected to cause more and more damage. In addition, the frequency, duration, and severity of drought can lead to different consequences [2]. Many factors such as rapid population growth, agricultural irrigation, industrial development, pollution of water resources, reduction of green areas, and climate change increase the severity of drought. The prolongation of the drought period is another factor that increases the unwelcome effects of drought. For these reasons, issues related to drought have been discussed in many parts of the world.

Wilhite and Glantz [3] divided drought into four categories, namely meteorological, agricultural, hydrological, and socio-economic droughts. Meteorological drought is the occurrence of less than normal precipitation for a specified period. Agricultural drought is closely related to various characteristics of meteorological drought. Agricultural drought is defined as the lack of water in soil moisture, while hydrological drought is defined as the lack of water in surface and subsurface water supplies such as rivers, lakes, reservoirs, and groundwater [4]. Agricultural drought usually happens after or during meteorological drought but before a hydrological drought. On the other hand, socio-economic drought is a type of drought that affects human life in terms of supply of and demand for economic goods. It is based on the impact of meteorological, agricultural, or hydrological drought. All types of droughts are caused by a lack of precipitation or meteorological drought. In other words, meteorological drought is the root cause of drought leading to other types of drought.

The effect of drought is increasing day by day in Turkey, located in the Mediterranean basin, where climate change impacts are greatest, as well as in the whole world. Recently, there has been a great meteorological drought in Turkey due to the increasing temperatures and decreasing precipitation as a result of climate change as well as global warming. Considering increasing population growth, Turkey may face the risk of becoming a water-poor country. All these factors have increased the importance of monitoring, assessment, and prediction of drought. Various studies have been carried out by researchers to assess drought variability, determine the impact of drought, and provide solutions [5-12]. Many drought indices are used to evaluate meteorological drought, such as the Standardized Precipitation Index (SPI) [13-18], the Standardized Precipitation Evaporation Index (SPEI) [17-19], the Palmer Drought Severity Index (PDSI) [20], the Reconnaissance Drought Index (RDI) [21], the Percent of Normal Index (PNI) [22], the Standardized Weighted Average of Precipitation Index (SWAP) [23], China-Z Index (CZI) [24], Discrepancy Precipitation Index (DPI) [25], and so on. Among these, the SPI and SPEI are the most commonly used meteorological drought assessment indices worldwide [26]. The results obtained by using these drought indices also provide knowledge about the drought trends (increasing or decreasing).

Bibliometric analysis is a quantitative research method that can be used in almost all scientific fields. It provides information on the general overview of a research field according to publications, authors, journals, citations, and so forth. In this respect, bibliometric analysis can offer researchers an opportunity to determine how and in which direction the studies in a field can be improved. In recent years, few bibliometric studies have been found in the literature related 
to the field of drought research. Hasan et al. conducted a bibliometric analysis to determine current trends, recognize patterns, and predict future directions in the field of hydrological drought. 76 publications published between 2000 and 2018 were analyzed in 3 main fields, namely drought severity, drought vulnerability, and drought prediction. Out of a total of 76 publications, about $55 \%$ were represented by the drought severity, about $26 \%$ by drought sensitivity, and about $19 \%$ by drought prediction. The results showed an increasing trend in publications related to hydrological drought [27]. Adisa et al. [28] performed a bibliometric analysis of 332 scientific studies published on drought monitoring and prediction in Africa from 1980 to 2020. The results revealed that about $75 \%$ of these publications were related to agricultural and hydrological drought studies, and the remaining $25 \%$ were related to socio-economic and meteorological drought studies. To our knowledge, there is no comprehensive and global bibliometric study focusing only on meteorological drought.

This study focuses on meteorological drought studies carried out on a global scale between 1980 and 2021. The publications in this field were obtained by searching the Scopus database. The main aim of this study is to determine the trends, current status, and knowledge gaps of studies in this field. To achieve this aim, a bibliometric analysis was conducted to identify the annual distribution of the publications, the most productive authors, the most publishing journals and countries, collaboration networks of authors and countries, the most used keywords and title words, the most cited journals and publications. Lotka's law, Price's law, and Pareto's law were used to determine author productivity. Collaboration networks among authors and countries were mapped graphically with the help of the VOSviewer software to further explain the results.

\section{Material and Methods}

The material for this study was obtained from the Scopus database. Figure 1 shows the flowchart of this study. The first step was to select the Scopus database for the publication search on a global scale. The second step was the selection of keywords. After deciding which keywords to use, publication research was conducted using Scopus. Keywords (TITLEABS) were searched in the publication title and abstract. As seen in Figure 1, a total of 3344 publications were found between 1980 and 2021. Of these 3344 publications, unrelated and duplicated 1998 publications were excluded. Finally, bibliometric analysis was performed with 1346 publications. The final results were presented through tables and figures. The process of identifying the publications included in this study and the bibliometric analysis used are explained in detailed the following sections, respectively. 
Searching the Scopus database using selected keywords

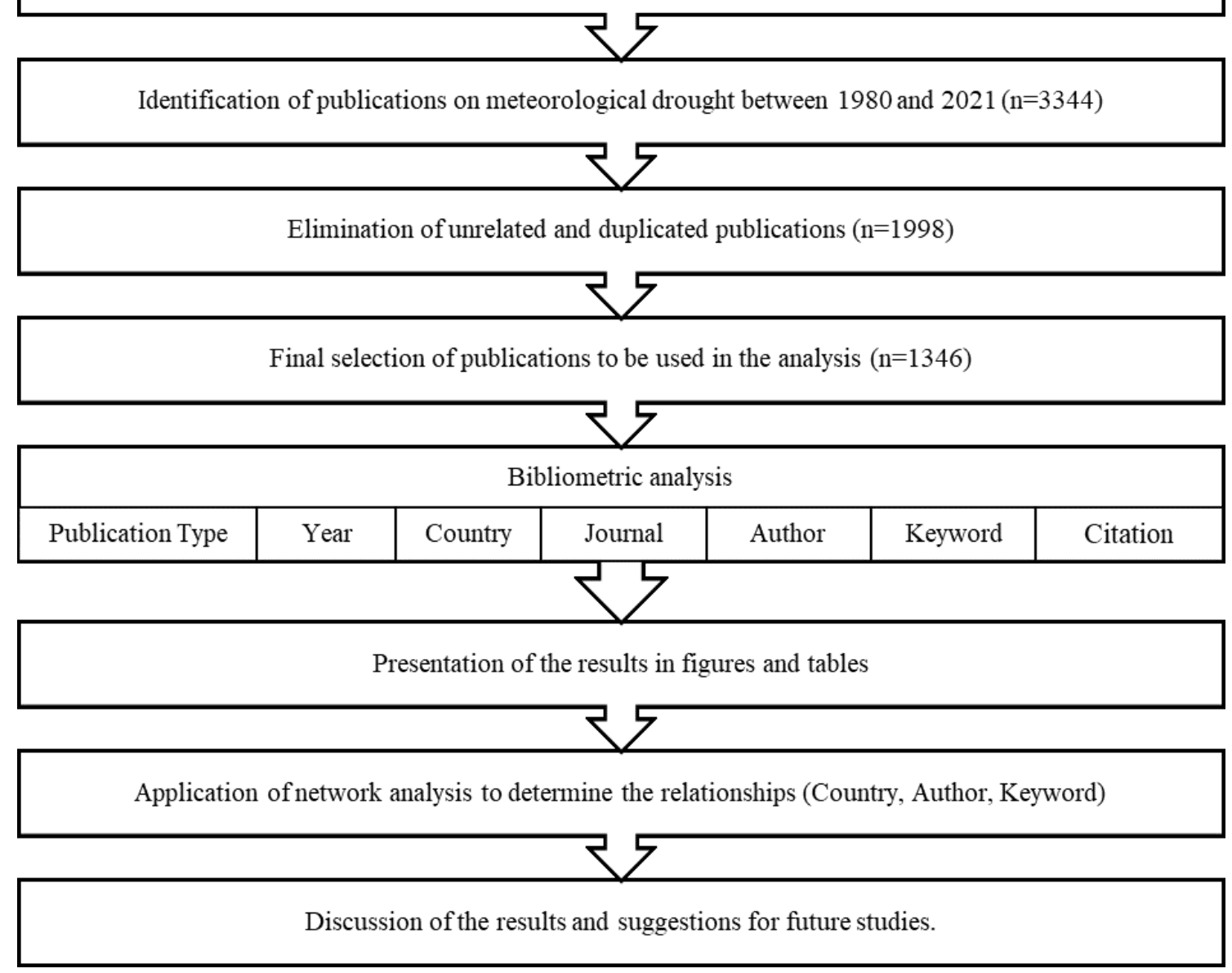

Figure 1. The flowchart for the search and identification of publications

\subsection{Data source and search criteria}

The data were obtained from the Scopus database on August 22, 2021. As seen in Table 1, searches were carried out in six different groups. In addition to the word "meteorological drought" found in all groups, selected keywords were included in the search as given in Table 1. These keywords were searched in the publication title and abstract.

The keywords "drought monitoring" and "drought analysis" were added to the search as drought studies have largely focused on these topics. The term "precipitation" was chosen as a keyword because it has a very significant effect on meteorological drought. Since drought indices are used as an important tool in meteorological drought monitoring studies, "drought index" OR "drought indices" was determined as a keyword. Standardized precipitation index (SPI) and standardized precipitation evapotranspiration index (SPEI) are two of the most widely used indices for detecting and characterizing meteorological droughts [29]. Therefore, these two indices were included in the search. Drought studies regarding the impact of climate change have also received more attention in recent years [30]. For this reason, the term "climate change" was also included in the search. As a result of the searches, a total of 3344 publications were obtained. The titles and abstracts of these publications were examined and those that were thought to be irrelevant were removed. Since some of the publications are in more than one search category, all duplicated publications were also removed. Finally, 1346 publications were identified to be used in the bibliometric analysis. 
Table 1. Keywords searched in the Scopus database and number of publications

\begin{tabular}{|c|c|}
\hline Keywords & Number of publications \\
\hline "meteorological drought" AND "precipitation" & 1161 \\
\hline "meteorological drought" AND "SPI" OR "SPEI" & 867 \\
\hline "meteorological drought" AND “drought index" OR "drought indices" & 567 \\
\hline "meteorological drought" AND "climate change" & 367 \\
\hline "meteorological drought" AND "drought monitor*" OR "monitor* drought" & 256 \\
\hline "meteorological drought" AND "drought analy*” OR "analy* drought" & 126 \\
\hline Total publications & 3344 \\
\hline
\end{tabular}

\subsection{Bibliometric analysis}

The concept of bibliometric analysis was first introduced by Pritchard [31]. It deals with the application of mathematical and statistical methods in order to analyze the publications in a research field [32]. Bibliometric analysis is a useful tool for revealing the global trends and future prospects of various research fields. In this study, various performance indicators were extracted for bibliometric analysis. The retrieved data from the Scopus database were analyzed in terms of publication type, the number of publications, year of publications, journal, author and country productivity, collaborations, citations, and keywords. The most frequently used bibliometric laws in the literature [33-38] were used to determine the scientific productivity of the authors. The authors and the number of publications were analyzed by Lotka's law, Price's law, and Pareto's law. According to Lotka's law, the number of authors publishing X publications is $1 / \mathrm{X}^{2}$ of those publishing one publication. This means that in a field, about $60 \%$ of the authors produce one publication, $15 \%$ of them produce two publications (1/2 times 60$), 7 \%$ of them produce three publications $\left(1 / 3^{2}\right.$ times 60$)$, and so on [36]. The purpose of this law is to define that fewer authors contribute to the majority of publications in the field, while a large number of authors contribute to the literature with one publication. Lotka's law was tested by using the chi-square method concerning the number of authors who contributed $\mathrm{X}$ number of publications in this study. The chisquare is calculated as $(\mathrm{O}-\mathrm{E})^{2} / \mathrm{E}$. $\mathrm{O}$ is the observed number of authors with $\mathrm{X}$ publications, and $\mathrm{E}$ is the expected number of authors. Price's law describes the relationship between the literature in the field and the number of authors in the field area. Price's law defines that the square root of the total number of authors publishing in the field contributes half of the total publications. [37]. Pareto's law, also known as the 80/20 rule, is used to identify the authors who contributed the most to the literature. According to Pareto's law, $80 \%$ of the total publications are produced by $20 \%$ of the total authors [38].

VOSviewer software was chosen in the study because it is a proficient tool for bibliometric analysis. VOSviewer software was used for constructing and visualizing bibliometric networks to understand relationships. Table 2 shows the types of analysis performed in the VOSviewer software. Herein, density and network visualization maps for coauthorship of authors and countries, co-occurrence of keywords, and title words were created. In co-occurrence analysis, the minimum number of occurrences of a keyword and title word was selected as 10 while in co-authorship analysis, the minimum number of publications of authors and countries was selected as 10. Taking Rodriguez et al. [39] as a reference, "Full counting" was chosen as the counting method in this analysis. The "Full counting" method means giving a score to each author with a full weight of one [40]. 
Table 2. Types of analysis using VOSviewer software

\begin{tabular}{ccc}
\hline Type of analysis & Unit of analysis & Counting method \\
\hline \multirow{2}{*}{ Co-authorship } & Authors & Full counting \\
& Countries & Full counting \\
\hline \multirow{2}{*}{ Co-occurrence } & Keywords & Full counting \\
& Title words & Full counting \\
\hline
\end{tabular}

\section{Results and Discussion}

The bibliometric analysis method was applied to the data obtained from the Scopus database, and the results are presented in this section.

\subsection{Types of publications}

Table 3 shows the distribution by publication type. Results indicated that out of 1346 publications, 88.71\% (1194) were articles, $9.51 \%$ (128) were conference papers, and $1.78 \%$ (24) were book chapters.

Table 3. Publication types considered in meteorological drought

\begin{tabular}{lll}
\hline Publication type & \# of publications & $\%$ \\
\hline Article & 1194 & 88.71 \\
Conference Paper & 128 & 9.51 \\
Book Chapter & 24 & 1.78 \\
\hline Total & 1346 & 100 \\
\hline
\end{tabular}

\subsection{Annual publications on meteorological drought from 1980 to 2021}

Figure 2 shows the distribution of 1346 publications in the field of meteorological drought from 1980 to August 2021. As can be seen in Figure 2, in period 1 (from 1980 to 2008), the publications were in the early growth stage. In period 2 (from 2008 to 2013), the number of publications started to increase despite a slight decrease between 2011 and 2012 . In period 3 (from 2013 to 2019), it was observed that the interest of the authors in this field increased gradually. While the number of publications was approximately 50 per year in period 2, the number of publications reached approximately 150 per year in period 3. In period 4, the number of publications increased sharply from 2019 to 2020 though there was a drop in 2021. The reason for the decrease in 2021 was due to the fact that the data used in the analysis were obtained until August 2021. By the end of 2021, it is predicted that the total number of publications in 2021 will exceed the one in 2020 . 


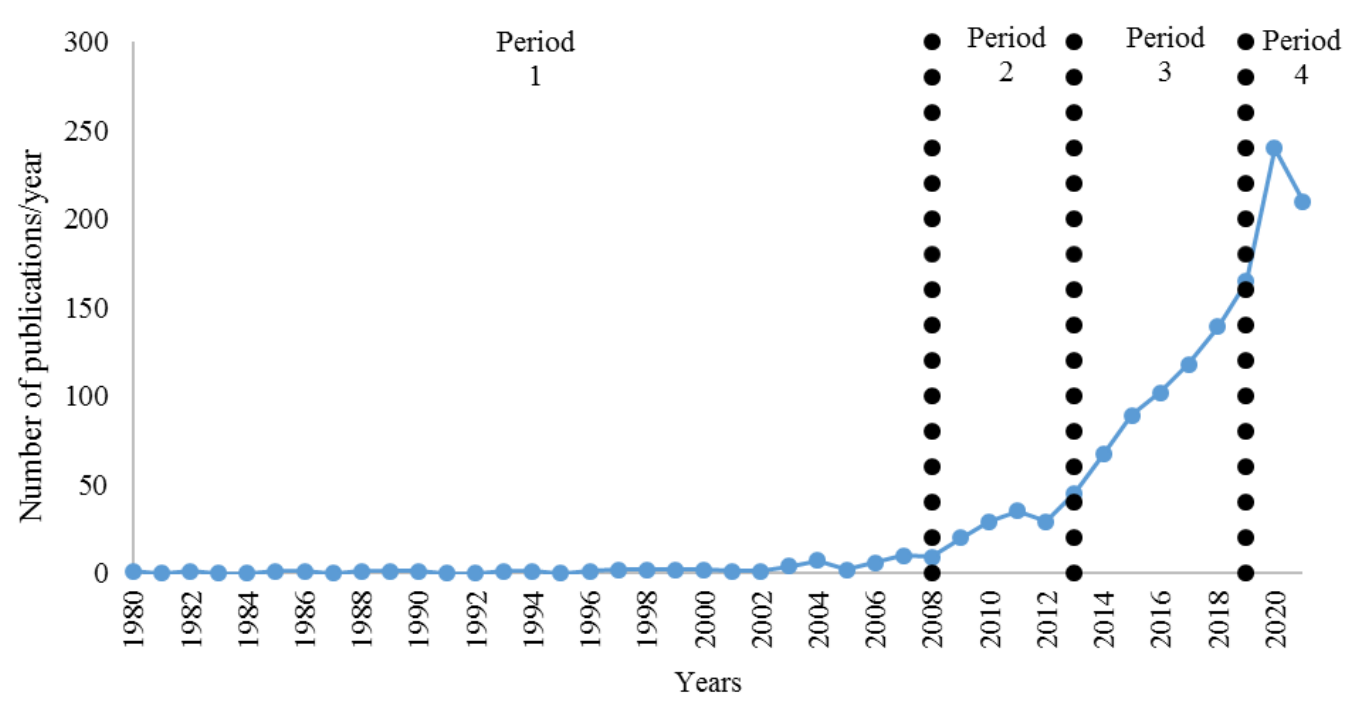

Figure 2. Distribution of publications in the field of meteorological drought by years

\subsection{Country analysis and collaborative network of countries}

Figure 3 shows the number of publications of the 10 most productive countries. All the publications were from 117 countries, among which China published the highest number of 410 publications, accounting for $30.46 \%$, followed by the United States (221 publications, 16.42\%), India (137 publications, 10.18\%), Iran (96 publications, 7.13\%) and the United Kingdom (75 publications, 5.57\%). Turkey ranked ninth among the 10 most productive countries with 48 publications.

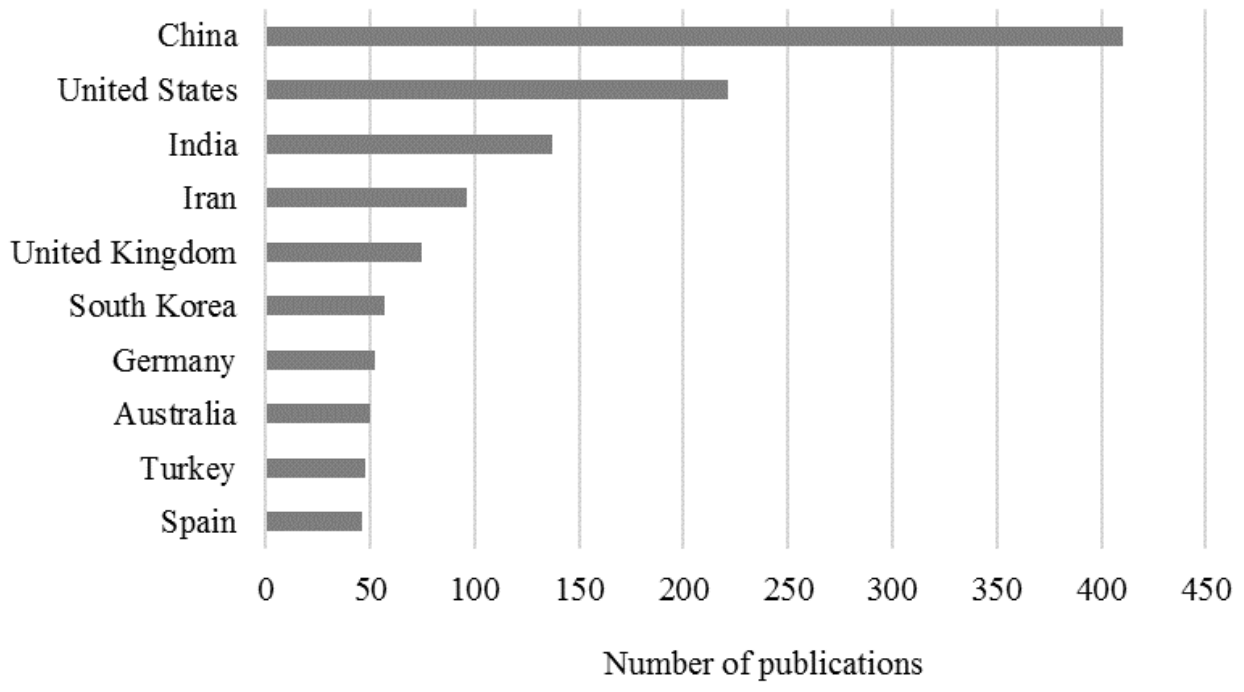

Figure 3. Top 10 most productive countries based on the total number of publications

Figure 4 shows the collaboration network among countries according to the number of publications. While creating the collaboration network among countries, the minimum number of publications of the countries was determined as 10. 38 out of 117 countries met this threshold. In the analysis, the VOSviewer software divided 38 countries into 5 clusters. 
The countries are indicated by the color of the cluster to which they belong. Those in the same color represent the countries in the same group. Cooperation among countries is described by the lines that join the countries. The thicker the line is, the greater the relationship becomes. On the other hand, the distance between the two circles reflects the strength of the relationship between the two circles. Shorter distances generally indicate stronger relationships. The number of publications by country is represented by the size of the circles. The higher the number of publications, the greater the size of the circle is. Based on the results, China was the most cooperating country. $30 \%$ of the total publications examined were made by Chinese authors.

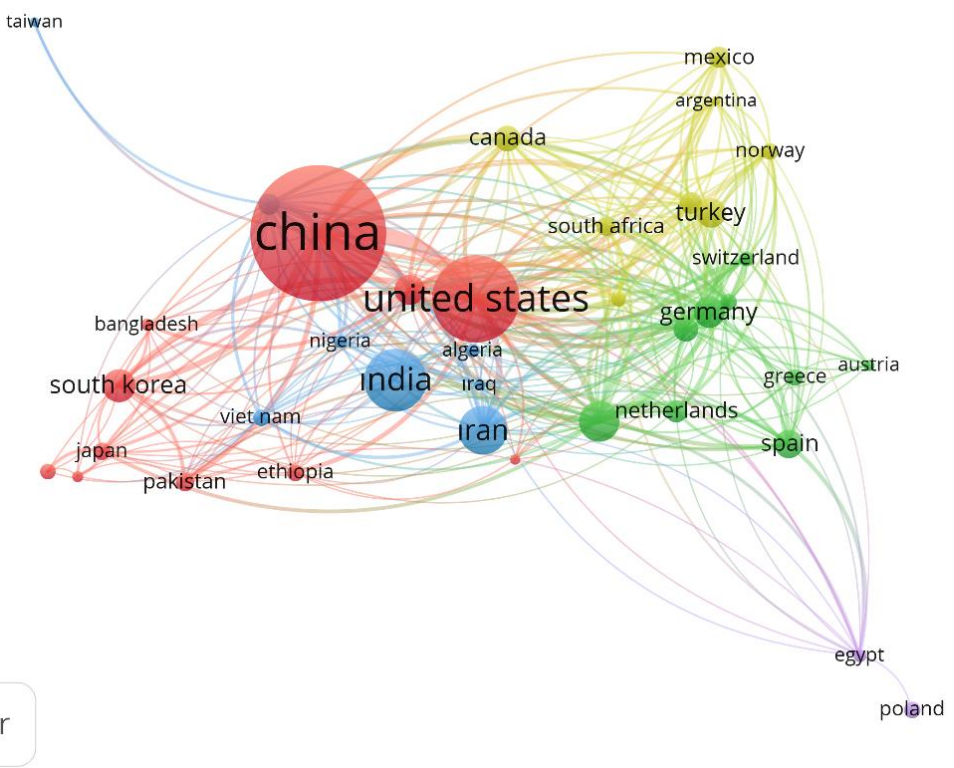

Figure 4. Network visualization map of country collaborations

\subsection{Journal analysis}

Studies on meteorological drought were published in 391 journals. The top ten journals were determined based on the number of publications (Table 4). Journal of Hydrology was ranked first, with 53 publications, accounting for 3.94\% of total publications. Water was ranked second with 50 publications $(3.71 \%)$, followed by the International Journal of Climatology with 46 publications $(3.42 \%)$.

Table 4. The top 10 journals based on the number of publications

\begin{tabular}{lccc}
\hline Journal & \# of publications & $\%$ & Country \\
\hline Journal of Hydrology & 53 & 3.94 & Netherlands \\
Water & 50 & 3.71 & Switzerland \\
International Journal of Climatology & 46 & 3.42 & United States \\
Natural Hazards & 45 & 3.34 & United States \\
Theoretical and Applied Climatology & 40 & 2.97 & Austria \\
Water Resources Management & 34 & 2.53 & Netherlands \\
Remote Sensing & 29 & 2.15 & Switzerland \\
Hydrology and Earth System Sciences & 27 & 2.01 & Germany \\
Arabian Journal of Geosciences & 25 & 1.86 & Germany \\
Hydrological Sciences Journal & 20 & 1.49 & England \\
\hline
\end{tabular}




\subsection{Author analysis and collaborative network of authors}

There was a total of 3682 authors in meteorological drought studies during the investigated period. $77.32 \%$ (2847 authors) of all authors published only one publication. Figure 5 shows the top ten authors according to the number of publications. Liu, Y. ranked first with 28 publications, followed by Wang, Y. with 23 publications, and Singh, V.P. with 21 publications.

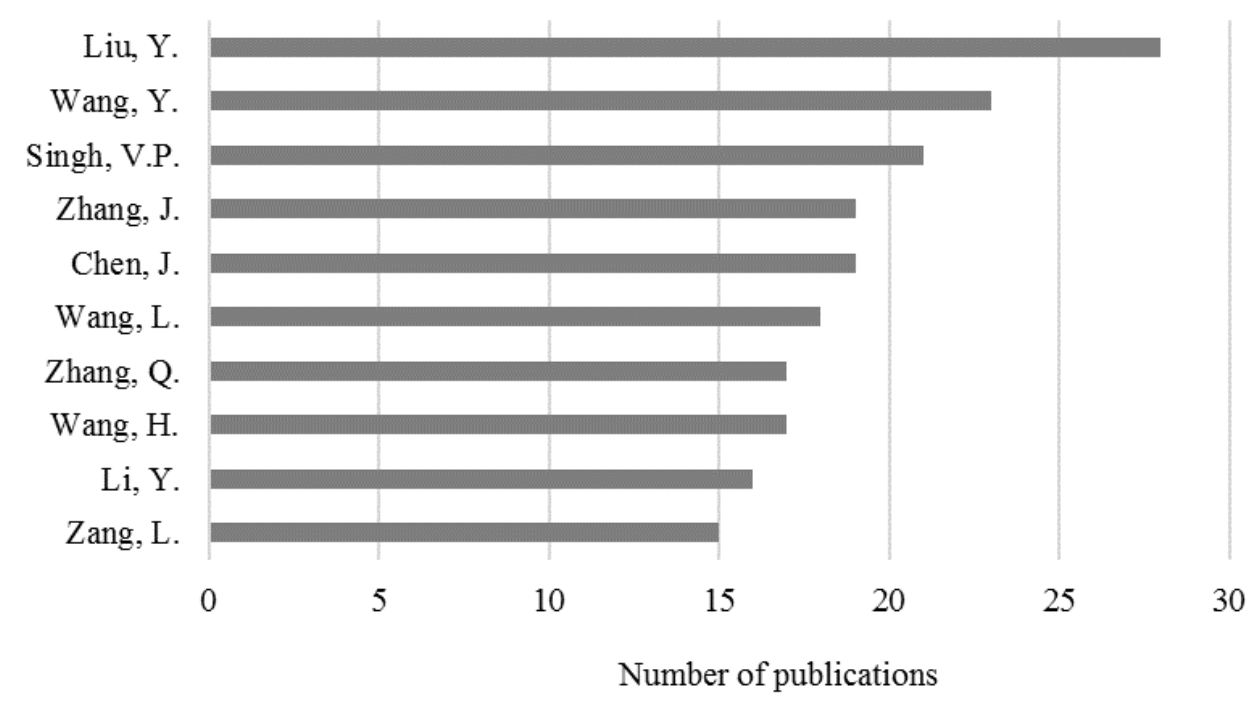

Figure 5. The top 10 productive authors based on the number of publications

The collaboration network according to the number of publications of the authors is given in Figure 6 . While creating the collaboration networks between the authors, the minimum number of publications of the authors was determined as 10. 29 out of 3682 authors met this threshold value. However, 4 authors had no joint network with other authors; for this reason, the network visualization map includes 25 authors. VOSviewer software divided 25 authors into 5 clusters. Those in the same color represent the authors in the same group.

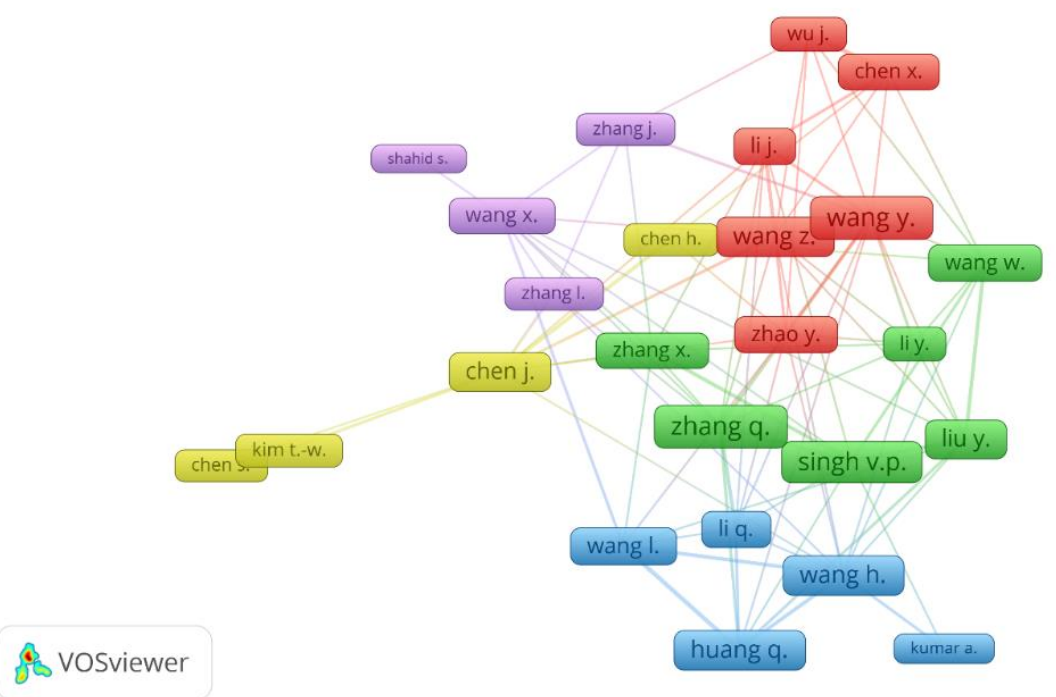

Figure 6. Network visualization map of author collaborations 
According to Pareto's law, 80\% of 1346 publications (1077 publications) should come from 20\% of 3682 authors (736 authors). However, it was seen that $20 \%$ of the authors produced $47.42 \%$ of the total publications with 638 publications. Therefore, the number of publications of the authors did not comply with the Pareto's law.

Table 5 shows the applicability of Lotka's law to evaluate the authors' productivity. The number of authors who produced more than 10 publications was quite small (only $0.6 \%$ ). The applicability of Lotka's law was tested with the chi-square test to compare the observed values with the expected values [34]. The calculated chi-square $\left(\chi^{2}=497.583\right)$ was higher than the chi-square of the table (32.671) at a degree of freedom of 21 and a level of significance at 0.05 . Thus, it was found out that the author distribution of the publications did not comply with Lotka's law.

Table 5. Lotka's law of author productivity

\begin{tabular}{|c|c|c|c|}
\hline $\begin{array}{l}\text { \# of publications } \\
\text { (X) }\end{array}$ & $\begin{array}{c}\text { \# of authors with } \\
\text { X publications } \\
(\mathrm{O})\end{array}$ & $\begin{array}{c}\text { Expected } \\
\text { \# of authors } \\
\text { (E) }\end{array}$ & $(\mathrm{O}-\mathrm{E})^{2} / \mathrm{E}$ \\
\hline 1 & 2847 & 2847 & 0.000 \\
\hline 2 & 474 & 712 & 79.417 \\
\hline 3 & 149 & 316 & 88.516 \\
\hline 4 & 81 & 178 & 52.810 \\
\hline 5 & 43 & 114 & 44.116 \\
\hline 6 & 26 & 79 & 35.631 \\
\hline 7 & 14 & 58 & 33.475 \\
\hline 8 & 11 & 44 & 25.204 \\
\hline 9 & 8 & 35 & 20.969 \\
\hline 10 & 7 & 28 & 16.191 \\
\hline 11 & 1 & 24 & 21.571 \\
\hline 12 & 2 & 20 & 15.973 \\
\hline 13 & 6 & 17 & 6.983 \\
\hline 14 & 3 & 15 & 9.145 \\
\hline 15 & 1 & 13 & 10.732 \\
\hline 16 & 1 & 11 & 9.211 \\
\hline 17 & 2 & 10 & 6.257 \\
\hline 18 & 1 & 9 & 6.901 \\
\hline 19 & 2 & 8 & 4.394 \\
\hline 21 & 1 & 6 & 4.611 \\
\hline 23 & 1 & 5 & 3.568 \\
\hline 28 & 1 & 4 & 1.907 \\
\hline Total & 3682 & & $\chi^{2}=497.583$ \\
\hline
\end{tabular}

Table 6 shows the applicability of Price's law to evaluate the authors' productivity. It was found that $77.32 \%$ of the authors (2847 authors) contributed $50.72 \%$ of total contributions. It was identified that the square root of total authors (62 authors) was $12.04 \%$ of the total contributions, which was much less than $50 \%$ of the literature in the field. Therefore, the result did not fulfill Price's law.

Authors with only one publication were dominant in the study. For this reason, the number of examined authors and the number of publications did not comply with all three laws. This indicated that there were very few productive authors in the field. Perhaps the authors who have only one publication in the relevant field may have turned to other fields. 
Table 6. Price's law of author productivity

\begin{tabular}{|c|c|c|c|c|}
\hline $\begin{array}{c}\text { \# of contributions } \\
\text { by each author }\end{array}$ & \# of authors $(\mathrm{N})$ & $\%$ & Total contributions & $\%$ \\
\hline 28 & 1 & 0.027 & 28 & 0.499 \\
\hline 23 & 1 & 0.027 & 23 & 0.410 \\
\hline 21 & 1 & 0.027 & 21 & 0.374 \\
\hline 19 & 2 & 0.054 & 38 & 0.677 \\
\hline 18 & 1 & 0.027 & 18 & 0.321 \\
\hline 17 & 2 & 0.054 & 34 & 0.606 \\
\hline 16 & 1 & 0.027 & 16 & 0.285 \\
\hline 15 & 1 & 0.027 & 15 & 0.267 \\
\hline 14 & 3 & 0.081 & 42 & 0.748 \\
\hline 13 & 6 & 0.163 & 78 & 1.390 \\
\hline 12 & 2 & 0.054 & 24 & 0.428 \\
\hline 11 & 1 & 0.027 & 11 & 0.196 \\
\hline 10 & 7 & 0.190 & 70 & 1.247 \\
\hline 9 & 8 & 0.217 & 72 & 1.283 \\
\hline 8 & 11 & 0.299 & 88 & 1.568 \\
\hline 7 & 14 & 0.380 & 98 & 1.746 \\
\hline Sub Total & 62 & 1.684 & 676 & 12.043 \\
\hline 6 & 26 & 0.706 & 156 & 2.779 \\
\hline 5 & 43 & 1.168 & 215 & 3.830 \\
\hline 4 & 81 & 2.200 & 324 & 5.772 \\
\hline 3 & 149 & 4.047 & 447 & 7.964 \\
\hline 2 & 474 & 12.873 & 948 & 16.889 \\
\hline 1 & 2847 & 77.322 & 2847 & 50.722 \\
\hline Total & 3682 & 100 & 5613 & 100 \\
\hline
\end{tabular}

\subsection{Keywords and title analysis}

One of the first and most important elements for readers is the title of the publication. The title of the publication gives the readers an idea about the focus and scope of the study. Figure 7 shows the density visualization map of the cooccurrence of title words. The minimum number of occurrences of a title word was selected as 10. Colors represent groups of terms that are strongly related to each other. Title words in the red zones appear more often, while title words in green zones appear less frequently. From this map, it was found that the main title words in red zones were "drought", "meteorological drought", "analysis", and "China". Another title word in the red zone was "climate change". This indicated that there were many studies investigating the impact of climate change on drought. 


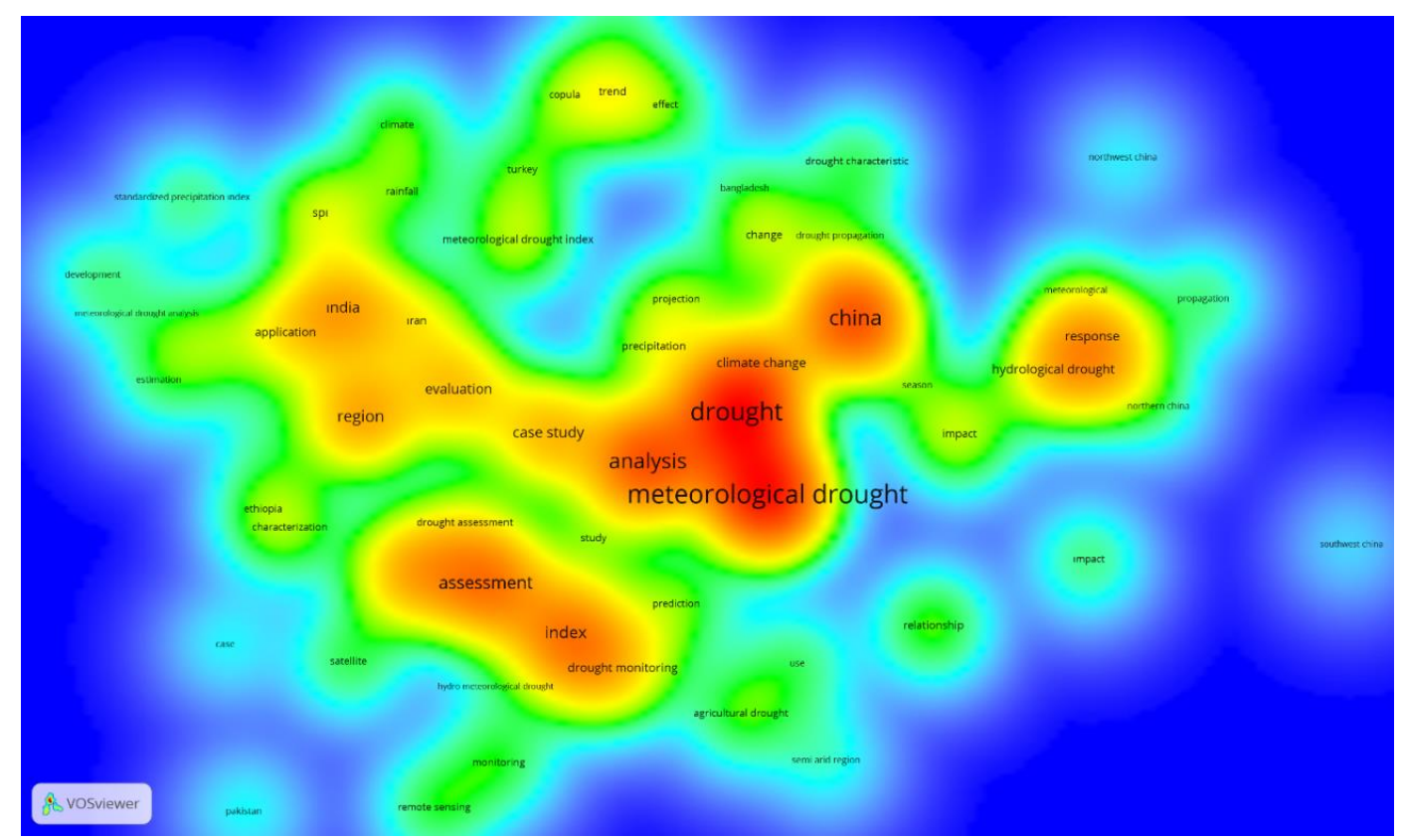

Figure 7. Density visualization map of the co-occurrence of title words

One of the most important bibliometric analysis methods is the analysis of keywords, which provides a summary representation of the content of a publication. Figure 8 shows the co-occurrence of keywords on the network visualization map. The minimum number of occurrences of a keyword was selected as 10. Colors represent groups of terms that are strongly related to each other. When keywords were examined in terms of co-occurrence networks, findings revealed that the biggest node was "drought". This means that the most recurring keyword was drought. As seen in Figure 8, the keywords were grouped into six clusters. These clusters were represented by circles of different colors and sizes. The most frequently used keywords were "drought" (394 times), "SPI" or "standardized precipitation index" (342 times), and "meteorological drought" (281 times). The issue of climate change was also frequently addressed in meteorological drought studies, in which "climate change" was the fourth mostly used keyword, with 127 occurrences.

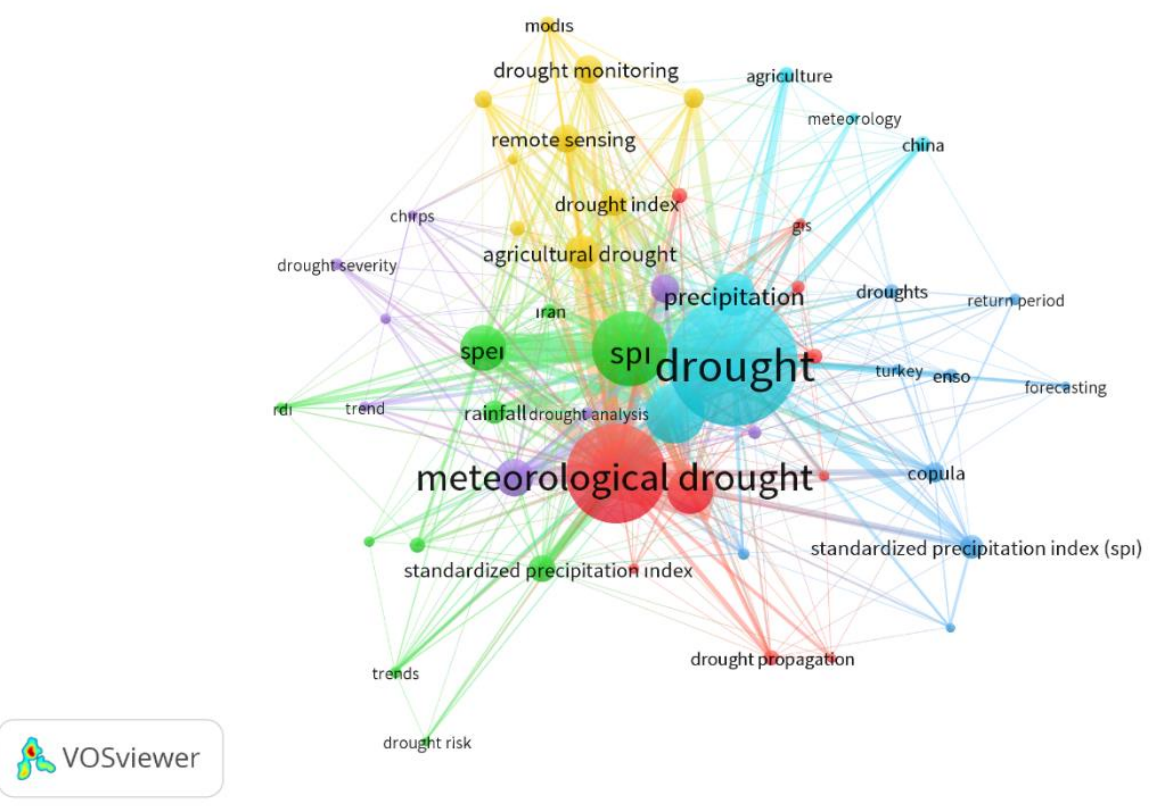

Figure 8. Network visualization map of the co-occurrence of keywords 


\subsection{Citation analysis}

The impact of the examined publications is analyzed in terms of the number of citations, as shown in Table 7. The total citations count per year is shown in Table 7. The publications were cited 24710 times in total. The number of the total citations for these publications was highest in the year 2020 (5448 citations). With regard to citations per publication, the number of citations was highest for publications published in 2021 (24.49 citations). Since all publications in 2021 were not included in the study, it is predicted that the number of citations will increase at the end of 2021.

Table 7. Annual citation analysis

\begin{tabular}{ccccc}
\hline Year & \# of publications & \# of citations & $\%$ & Citations per publication \\
\hline $1980-2016$ & 474 & 5817 & 23.54 & 12.27 \\
2017 & 118 & 1995 & 8.07 & 16.91 \\
2018 & 139 & 2639 & 10.68 & 18.99 \\
2019 & 165 & 3669 & 14.85 & 22.24 \\
2020 & 240 & 5448 & 22.05 & 22.70 \\
2021 & 210 & 5142 & 20.81 & 24.49 \\
\hline Total & 1346 & 24710 & 100 & \\
\hline
\end{tabular}

The general citation structure of the publications is shown in Table 8. As seen in Table 8, there were 290 publications $(21.55 \%)$ that were never cited. The majority of the publications (75.18\%) were cited between 1 and 99 times.

Table 8. General citation structure of the publications citing the selected journals

\begin{tabular}{ccc}
\hline \# of citations & \# of publications & $\%$ \\
\hline$\geq 500$ & 2 & 0.15 \\
$499-400$ & 2 & 0.15 \\
$399-300$ & 3 & 0.22 \\
$299-200$ & 9 & 0.67 \\
$199-100$ & 28 & 2.08 \\
$99-1$ & 1012 & 75.18 \\
0 & 290 & 21.55 \\
\hline Total & 1346 & 100 \\
\hline
\end{tabular}

Table 9 lists the most cited publications. The most cited publication was titled "Accepting the standardized precipitation index: A calculation algorithm”. It was published in 1999 and cited 783 times, as shown in Table 9. 
Table 9. Top 10 most cited publications

\begin{tabular}{|c|c|c|c|}
\hline Publication title & $\begin{array}{c}\text { \# of } \\
\text { citations }\end{array}$ & Author(s) & $\begin{array}{c}\text { Publication } \\
\text { year }\end{array}$ \\
\hline $\begin{array}{l}\text { "Accepting the standardized precipitation index: A } \\
\text { calculation algorithm" }\end{array}$ & 783 & Guttman [41] & 1999 \\
\hline $\begin{array}{l}\text { "Assessing vegetation response to drought in the } \\
\text { northern Great Plains using vegetation and drought } \\
\text { indices" }\end{array}$ & 514 & Ji and Peters [42] & 2003 \\
\hline "A review of drought indices" & 469 & Zargar et al. [43] & 2011 \\
\hline $\begin{array}{l}\text { "Modelling the recent evolution of global drought and } \\
\text { projections for the twenty-first century with the } \\
\text { Hadley Centre climate model" }\end{array}$ & 407 & Burke et al. [44] & 2006 \\
\hline $\begin{array}{l}\text { "Regional drought assessment based on the } \\
\text { Reconnaissance Drought Index (RDI)" } \\
\text { "The Lincoln declaration on drought indices: }\end{array}$ & 398 & Tsakiris et al. [21] & 2007 \\
\hline $\begin{array}{l}\text { Universal meteorological drought index } \\
\text { recommended" }\end{array}$ & 388 & Hayes et al. [45] & 2011 \\
\hline "Assessment of hydrological drought revisited" & 370 & Nalbantis and Tsakiris [46] & 2009 \\
\hline $\begin{array}{l}\text { "Evaluation of drought indices based on Thermal } \\
\text { remote sensing of evapotranspiration over the } \\
\text { continental United States" }\end{array}$ & 270 & Anderson et. al [47] & 2011 \\
\hline $\begin{array}{l}\text { "Candidate Distributions for Climatological Drought } \\
\text { Indices (SPI and SPEI)" }\end{array}$ & 256 & Stagge et al. [48] & 2015 \\
\hline "Land surface processes and Sahel climate" & 243 & Nicholson [49] & 2000 \\
\hline
\end{tabular}

Figure 9 shows journals with at least 1000 citations. The publications from the top four journals (journals cited at least 1000 times) were cited 5263 times. Those from the Water Resources Management and Journal of Hydrology were cited 1710 and 1335 times, respectively. According to the average number of citations per publication, the Remote Sensing of Environment was in the first place with 143 (1144 citations divided by eight publications), followed by Water Resources Management with 50.29 (1710 citations divided by 34 publications).

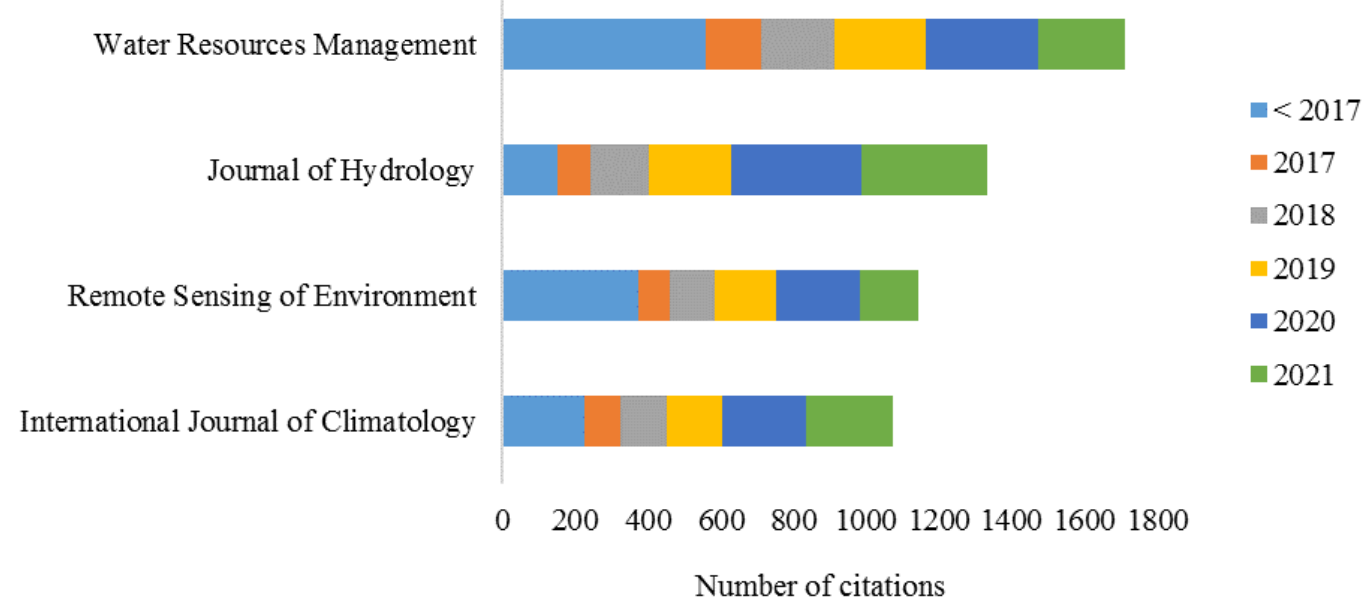

Figure 9. Citations of the top four journals with the most cited publications 


\section{Conclusion}

This study aims to present a comprehensive analysis of the meteorological drought-related literature published from 1980 to August 2021 based on the Scopus database. To achieve this aim, bibliometric analysis was used since it plays an important role in the decision-making process related to science. The annual distribution of the publications, the most productive authors, the most publishing journals and countries, collaboration of authors and countries, the most used keywords and title words, the most cited journals and publications were identified. The results showed that the most productive authors came from countries such as China, the United States, and India. Turkey was the ninth country among 117 countries in terms of the most productive authors. The most productive author was Liu, Y. with 28 publications. A total of 3682 authors engaged in studies of meteorological drought. According to statistics, it was found that there were 2847 authors with only one publication, accounting for $77.32 \%$ of the authors. The applicability of Lotka's law was tested with the chi-square test. It was seen that the number of authors and publications did not comply with Lotka's law, Price's law, and Pareto's law. Furthermore, the results of Lotka's law, Price's law, and Pareto's law revealed that there were a few highly productive authors and a great majority who only occasionally contribute. The journal with the highest number of publications on meteorological drought studies was the Journal of Hydrology. The journal with the most citations in this field was Water Resources Management. It was observed that the most used keywords were "drought", "SPI" or "standardized precipitation index", "meteorological drought", and the most used words in the title were drought, meteorological drought, and analysis. Another important word used in both keywords and titles is "climate change". The presence of "climate change" among the most used words shows that it is an important concept in studies of drought. From 1980 to 2021, 1346 publications were cited a total of 24710 times. In the last three years, the number of citations to publications was about $60 \%$ of the total number of citations. This shows that the productivity in this field has increased considerably in recent years. The number of publications has also increased considerably after 2019. The increase in the number of publications and citations indicates that studies on meteorological drought have gained international importance in recent years. For this reason, authors should be encouraged and supported to produce more publications in this field. Also, collaboration networks among authors can be developed.

The results of the bibliometric analysis with more than 1300 publications examined in this study are considered to be a reliable indicator. Understanding the current knowledge about meteorological drought is expected to be a guide for future studies in this field. The study is limited to meteorological drought studies in the Scopus database. Therefore, studies on hydrological, agricultural, and socio-economic drought can be included in future studies. Results from different databases can be compared. The results of this study can be further enriched by adding content analysis.

\section{References}

[1] Safarianzengir, V., Sobhani, B., Madadi, A. and Yazdani, M. (2021). Monitoring, analyzing and estimation of drought rate using new fuzzy index in cities of west and southwest of Iran, located in the north of the Persian gulf. Environment, Development and Sustainability, 23(5): 7454-7468.

[2] Spinoni, J., Vogt, J. V., Naumann, G., Barbosa, P. and Dosio, A. (2018). Will drought events become more frequent and severe in Europe?. International Journal of Climatology, 38(4): 1718-1736. 
[3] Wilhite, D. A. and Glantz, M. H. (1985). Understanding: the drought phenomenon: the role of definitions. Water international, 10(3): 111-120.

[4] Mishra, A. K. and Singh, V. P. (2010). A review of drought concepts. Journal of hydrology, 391(1-2): 202216.

[5] Wu, J., Zhou, L., Mo, X., Zhou, H., Zhang, J. and Jia, R. (2015). Drought monitoring and analysis in China based on the Integrated Surface Drought Index (ISDI). International Journal of Applied Earth Observation and Geoinformation, 41: 23-33.

[6] Vaheddoost, B. and Safari, M. J. S. (2021). Application of Signal Processing in Tracking Meteorological Drought in a Mountainous Region. Pure and Applied Geophysics, 178: 1943-1957.

[7] Altin, T. B. and Altin, B. N. (2021). Response of hydrological drought to meteorological drought in the eastern Mediterranean Basin of Turkey. Journal of Arid Land, 13(5): 470-486.

[8] Anandharuban, P. and Elango, L. (2021). Spatio-temporal analysis of rainfall, meteorological drought and response from a water supply reservoir in the megacity of Chennai, India. Journal of Earth System Science, 130(1): 1-20.

[9] Yaltı, S. and Aksu, H. (2019). Drought Analysis of Iğdır Turkey. Turkish Journal of Agriculture-Food Science and Technology, 7(12): 2227-2232.

[10] Dalkilic, H. Y., Bayçinar, M. and Samui, P. (2021). Evaluation of combined use of drought indices in the case of Konya Closed Basin. International Journal of Global Warming, 23(2): 169-190.

[11] Yihdego, Y., Vaheddoost, B. and Al-Weshah, R. A. (2019). Drought indices and indicators revisited. Arabian Journal of Geosciences, 12(3): 69.

[12] Yuce, M. I. and Esit, M. (2021). Drought monitoring in Ceyhan Basin, Turkey. Journal of Applied Water Engineering and Research, 1-22.

[13] McKee, T. B., Doesken, N. J. and Kleist, J. (1993). The relationship of drought frequency and duration to time scales. In Proceedings of the 8th Conference on Applied Climatology, 17(22): 179-183.

[14] Moghbeli, A., Delbari, M. and Amiri, M. (2020). Application of a standardized precipitation index for mapping drought severity in an arid climate region, southeastern Iran. Arabian Journal of Geosciences, 13(5): 1-16.

[15] Xu, K., Qin, G., Niu, J., Wu, C., Hu, B. X., Huang, G. and Wang, P. (2019). Comparative analysis of meteorological and hydrological drought over the Pearl River basin in southern China. Hydrology Research, 50(1): 301-318.

[16] Gumus, V. and Algin, H. M. (2017). Meteorological and hydrological drought analysis of the Seyhan- Ceyhan River Basins, Turkey. Meteorological Applications, 24(1): 62-73.

[17] Eris, E., Cavus, Y., Aksoy, H., Burgan, H. I., Aksu, H. and Boyacioglu, H. (2020). Spatiotemporal analysis of meteorological drought over Kucuk Menderes River Basin in the Aegean Region of Turkey. Theoretical and Applied Climatology, 142(3), 1515-1530.

[18] Mehr, A. D. and Vaheddoost, B. (2020). Identification of the trends associated with the SPI and SPEI indices across Ankara, Turkey. Theoretical and Applied Climatology, 139(3): 1531-1542.

[19] Vicente-Serrano, S. M., Beguería, S., Lorenzo-Lacruz, J., Camarero, J. J., López-Moreno, J. I., Azorin-Molina, C., ... and Sanchez-Lorenzo, A. (2012). Performance of drought indices for ecological, agricultural, and hydrological applications. Earth Interactions, 16(10): 1-27. 
[20] Palmer WC (1965). Meteorological drought, vol 30. US Department of Commerce, Weather Bureau, Washington.

[21] Tsakiris, G., Pangalou, D., and Vangelis, H. (2007). Regional drought assessment based on the Reconnaissance Drought Index (RDI). Water resources management, 21(5): 821-833.

[22] Willeke, G., Hosking, J. R. M., Wallis, J. R. and Guttman, N. B. (1994). The national drought atlas. Institute for water resources report, 94 .

[23] Liu, B., Liu, Y., Wang, W., and Li, C. (2021). Meteorological Drought Events and Their Evolution from 1960 to 2015 Using the Daily SWAP Index in Chongqing, China. Water, 13(14): 1887.

[24] Wu, H., Hayes, M. J., Weiss, A., and Hu, Q. I. (2001). An evaluation of the Standardized Precipitation Index, the China-Z Index and the statistical Z-Score. International Journal of Climatology: A Journal of the Royal Meteorological Society, 21(6): 745-758.

[25] Tayfur, G. (2021). Discrepancy precipitation index for monitoring meteorological drought. Journal of Hydrology, 597, 126174.

[26] Salimi, H., Asadi, E., and Darbandi, S. (2021). Meteorological and hydrological drought monitoring using several drought indices. Applied Water Science, 11(2): 1-10.

[27] Hasan, H. H., Mohd Razali, S. F., Muhammad, N. S., and Ahmad, A. (2019). Research trends of hydrological drought: A systematic review. Water, 11(11): 2252.

[28] Adisa, O. M., Masinde, M., Botai, J. O., and Botai, C. M. (2020). Bibliometric analysis of methods and tools for drought monitoring and prediction in Africa. Sustainability, 12(16): 6516.

[29] Li, L., She, D., Zheng, H., Lin, P., and Yang, Z. L. (2020). Elucidating diverse drought characteristics from two meteorological drought indices (SPI and SPEI) in China. Journal of Hydrometeorology, 21(7): 1513-1530.

[30] Danandeh Mehr, A., Sorman, A. U., Kahya, E., and Hesami Afshar, M. (2020). Climate change impacts on meteorological drought using SPI and SPEI: Case study of Ankara, Turkey. Hydrological Sciences Journal, 65(2): 254-268.

[31] Pritchard, A. (1969). Documentation notes? Journal of Documentation, 25(4): 344-349.

[32] Aria, M., and Cuccurullo, C. (2017). Bibliometrix: An R-tool for comprehensive science mapping analysis. Journal of informetrics, 11(4): 959-975.

[33] Sudhier, K. P. (2013). Lotka's Law and Pattern of Author Productivity in the Area of Physics Research. DESIDOC Journal of Library \& Information Technology, 33(6): 457-464.

[34] Rathika, N., Thanuskodi, S., and Sudhakar, K. (2020). Lotka's law and the pattern of scientific productivity in the marine pollution research. International Journal on Emerging Technologies, 11(2): 332-341.

[35] Yılmaz, M. (2008). Price Yasası ve Türkiye'de fikri mülkiyet hakları literatürü. Bilgi ve Belge Araştırmaları, (1): 23-38.

[36] Kumar, S., and Senthilkumar, R. (2019). Applicability of Lotka's law in astronomy \& astrophysics research of India. Library Philosophy and Practice, 1-13.

[37] Price, D. D. S. (1976). A general theory of bibliometric and other cumulative advantage processes. Journal of the American society for Information science, 27(5): 292-306. 
[38] Serdarasan, Ş., Yılmaz, H., Doğan, E., Koç, B., Kayır, M., and Çatalyürek, M. (2021). Lojistik ve Tedarik Zinciri Alanında TR Dizin'de İndekslenen Çalışmaların Bibliyometrik Analizi. Dumlupınar Üniversitesi Sosyal Bilimler Dergisi , (68): 164-184.

[39] Perianes-Rodriguez, A., Waltman, L., and Van Eck, N. J. (2016). Constructing bibliometric networks: A comparison between full and fractional counting. Journal of Informetrics, 10(4), 1178-1195.

[40] Van Eck, N. J., and Waltman, L. (2010). Software survey: VOSviewer, a computer program for bibliometric mapping. Scientometrics, 84(2), 523-538.

[41] Guttman, N. B. (1999). Accepting the standardized precipitation index: a calculation algorithm 1. JAWRA Journal of the American Water Resources Association, 35(2): 311-322.

[42] Ji, L., and Peters, A. J. (2003). Assessing vegetation response to drought in the northern Great Plains using vegetation and drought indices. Remote Sensing of Environment, 87(1): 85-98.

[43] Zargar, A., Sadiq, R., Naser, B., and Khan, F. I. (2011). A review of drought indices. Environmental Reviews, 19: 333-349.

[44] Burke, E. J., Brown, S. J., and Christidis, N. (2006). Modeling the recent evolution of global drought and projections for the twenty-first century with the Hadley Centre climate model. Journal of Hydrometeorology, 7(5): 1113-1125.

[45] Hayes, M., Svoboda, M., Wall, N., and Widhalm, M. (2011). The Lincoln declaration on drought indices: universal meteorological drought index recommended. Bulletin of the American Meteorological Society, 92(4): 485-488.

[46] Nalbantis, I., and Tsakiris, G. (2009). Assessment of hydrological drought revisited. Water resources management, 23(5): 881-897.

[47] Anderson, M. C., Hain, C., Wardlow, B., Pimstein, A., Mecikalski, J. R., and Kustas, W. P. (2011). Evaluation of drought indices based on thermal remote sensing of evapotranspiration over the continental United States. Journal of Climate, 24(8): 2025-2044.

[48] Stagge, J. H., Tallaksen, L. M., Gudmundsson, L., Van Loon, A. F., and Stahl, K. (2015). Candidate distributions for climatological drought indices (SPI and SPEI). International Journal of Climatology, 35(13): 4027-4040.

[49] Nicholson, S. (2000). Land surface processes and Sahel climate. Reviews of Geophysics, 38(1): 117-139. 